\title{
The Show-Up Identification Procedure: A Literature Review
}

\author{
Mattias Per Sjöberg \\ Department of Psychology, Queen's University, Kingston, Canada \\ Email: matte190@hotmail.com
}

Received 23 December 2015; accepted 25 January 2016; published 28 January 2016

Copyright (C) 2016 by authors and Scientific Research Publishing Inc.

This work is licensed under the Creative Commons Attribution International License (CC BY). http://creativecommons.org/licenses/by/4.0/

c) (i) Open Access

\begin{abstract}
A show-up is an identification procedure that only presents the witness with one suspect in contrast to a lineup where the suspect is presented among a number of fillers (i.e., known innocent people). This feature makes the show-up procedure very suggestive. In this literature review, an overview of the current research about this identification procedure is presented. The different factors that influence the accuracy in show-up procedures are separated into system (e.g., clothing bias, instruction bias, and the impact of multiple show-ups) and estimator variables (e.g., age, cross-race effects, and alcohol) in line with Wells [1]. The implications of the research are discussed together with suggestions for future research.
\end{abstract}

\section{Keywords}

Show-Up, Identification Accuracy, Eyewitness Identification, System Variables, Estimator Variables

\section{Introduction}

When a witness is asked to identify a person that has committed a crime, police may use a lineup procedure where the suspect is placed among a number of fillers (known innocent people) and asked to select the person that best matches his or her description of the perpetrator. Another, yet still much more unexplored identification procedure is the show-up procedure. Here witnesses are presented with only one photo or person and asked whether this person is the real perpetrator [2]. A recent study finds that show-ups are used by both American and Canadian police officers and that they are most common among the American police officers [3]. Thus, because the show-up procedure is frequently used, research about this identification procedure is warranted. This literature review will give an overview of the science of show-up identifications and the factors (i.e., system and estimator variables) that have been demonstrated to influence its accuracy. The system variables that will be reviewed include live show-up, clothing bias, instruction bias, time delay, and the impact of multiple show-ups 
while the estimator variables include age, cross-race effects, weapon focus, and alcohol.

One of the things that are strikingly clear when going through the literature about eyewitness identification is that the research about the show-up procedure has not been nearly as widely researched compared to the investigation about different lineup procedures. Indeed, a meta-analysis by Steblay, Dysart, Fulero, and Lindsay [4] is only able to find eight studies involving the show-up procedure (seven published and one unpublished). This can be contrasted to a recent meta-analysis of the difference between the simultaneous versus sequential lineup procedure that included 49 different studies with 72 (nonindependent) tests [5].

When police are presenting a show-up to a witness, two different results are possible [6]: the witness can make a correct identification or an incorrect rejection (if the show-up contains the perpetrator) or the witness can make a correct rejection or a false identification (if the show-up does not contain the perpetrator). This obviously makes the show-up procedure very suggestive since the identity of the suspect is known to the witness throughout the entire procedure [3]. Other scholars have also pointed out the suggestiveness of the show-up procedure. For example, police officers who administer show-ups sometimes say things like "we have found the suspect and want you to take a look" or "we catch the perpetrator and are bringing him for you to identify him" ([7], p. 129). Statements like these make it painfully clear that the suggestiveness of the show-up procedure can be very high and that police occasionally make it even more suggestive (probably unintentionally). This is something that, which we will see, also affects the probability of witnesses identifying innocent suspects.

One further problem with the show-up procedure is that it cannot make use of double blind testing. In lineups, double blind testing refers to the situation when the person who administers the lineup does not know who the suspect is [8]. This can be traced back to the lineup-as-experiment analogy. This analogy states that a lineup is very similar to an experiment. As described by Wells et al. [8], the police have a hypothesis (that the suspect is guilty), they collect material that can be used to test this hypothesis (e.g., other evidence of the crime, pictures of the suspect and filler pictures to be used in a lineup), they make up a design (e.g., placing the picture of the suspect in position 3 in a lineup), tell the instructions to the subject (the witness), run the procedure (e.g., the lineup), record the data (suspect pick or not), and evaluate the hypothesis from the results of the data (decide whether the identification is enough evidence of guilt). The problem with the show-up procedure is that the witness (and the person who administers the procedure) always will know who the suspect is. Accordingly, it is impossible to conduct a double-blind show-up ${ }^{1}$.

\section{System and Estimator Variables}

In the science of eyewitness identification, two different types of variables have traditionally been studied in psychological laboratories around the world-system variables and estimator variables [1]. System variables include variables that are under the influence and control of the criminal justice system. This could cover things like the construction of the lineup, what instructions are given to the witness, and how the witness is interviewed. Estimator variables, on the other hand, are variables that are not under the control of the criminal justice system. These can include things like the race of the witness relative to the race of the perpetrator, whether there was a weapon involved in the crime, and how far from the crime scene the witness was when witnessing the crime. Wells [1] argued that since system variables have the potential to be controlled or at least improved by the criminal justice system, research on system variables are more likely to lead to fruitful results compared to estimator variables. The administration of the show-up procedure could be characterized as a system variable (a variable under the control of the criminal justice system). However, as we will see, there are many estimator variables that influence the accuracy from show-ups as well as lineups.

\section{Absolute and Relative Decision Making}

Before going on to review the specific literature about show-ups, it is important to understand the difference between relative and absolute decision making processes. Wells [6] argued that when viewing a simultaneous lineup (i.e., a lineup where all members of the lineup are presented simultaneously), witnesses will tend to choose the lineup member who looks most like the perpetrator relative to the other members of the lineup. This is not a bad method if the perpetrator is included in the lineup but gets increasingly severe if the perpetrator is

${ }^{1}$ Even a single-blind show-up procedure is impossible to conduct. This is because the witness would always know that the presented person is the suspect (see [2] [3]). 
not included in the lineup (i.e., a target-absent lineup). Then the lineup member that looks most like the perpetrator is obviously at risk of being chosen. In order to reduce the use of a relative decision making process, Lindsay and Wells [9] invented the sequential lineup. Here witnesses are presented with the lineup members one at a time instead of all at the same time (i.e., simultaneously). This lineup procedure has been shown to greatly reduce the tendency of witnesses to choose an innocent lineup member [5] [9]. One reason for this is that witnesses are using an absolute decision making strategy (i.e., comparing each lineup member to their own memory of the perpetrator) instead of using a relative decision making strategy (i.e., comparing the lineup members to each other and choose the lineup member who looks most like the perpetrator).

It could be argued that a show-up procedure is more similar to a sequential lineup procedure and therefore, that show-ups should reduce the number of false identifications when compared to a simultaneous lineup. However, research suggests that the false identification rates of show-ups and lineups (simultaneous and sequential lineups) are about the same [4], indicating that there might be other factors involved in making the show-up procedure prone to putting innocent suspects at risk for being mistakenly identified. One such factor could be the suggestiveness of the show-up procedure. As laid out in Dysart and Lindsay [2], when a show-up is presented to a witness, it is clear who the suspect is (why would the police otherwise bother to show the picture to the witness?). Thus, some researchers have argued that the suggestiveness of the show-up procedure is very high. This is reflected in a survey of experts in the eyewitness area where only $74 \%$ of researchers believed the show-up procedure to be reliable enough for psychologists to present in court [10]. Despite the seemingly negative aspects of show-ups, Smith et al. [3] have argued that show-ups have several positive features that make them important to further investigate. For example, show-ups can be created very quickly and is not nearly as time consuming as creating a lineup. Thus, the procedure can be used to immediately exclude or identify a suspect as the potential perpetrator.

\section{Show-Up Outcomes}

Focusing on the results of the meta-analysis by Steblay et al. [4], it is initially interesting to compare the overall choosing rate between the two different mentioned identification procedures (i.e., show-ups and lineups). This can be done by collapsing the choosing responses for lineups to include both target present and target absent lineups. Doing so, it was demonstrated that witnesses were twice as likely (54\%) to choose from a lineup compared to a show-up procedure (27\%). This result would seem to go against the argument above that show-ups are inherently suggestive and instead provide support that they are actually less suggestive than lineups. However, there are different implications of choosing from a show-up as compared to choosing from a lineup. Since the show-up procedure only presents the witness with one suspect, all selections will be wrong given that the suspect is innocent [2]. In a lineup however, the innocent suspect is protected by the presence of the other lineup members (i.e., lineup fillers). If a fair lineup procedure is used, meaning that there is only one suspect and that all lineup members are similar to the description given by the witness [11], there is no reason for the suspect to be a more likely choice than any other of the lineup members (given that the suspect is innocent). This means that the proportion of false identifications of an innocent suspect from a properly conducted lineup should be the rate of all false-positive selections (i.e., the rate of identifying a filler or a suspect) divided by the number of people in the lineup. In other words, the proportion of false identifications of an innocent suspect will be much lower than the proportion of false-positive selections (i.e., identifying a filler). In contrast, for the show-up procedure, only one person is shown to the witness and thus all false-positive selections will also be false identifications [2]. This means that it is possible for the show-up procedure to generate much lower rates of false-positive selections while not improving the proportion of false identifications.

\section{Show-Up Accuracy}

With this overview of the possible outcomes of the show-up procedure we are in a better position to evaluate the research. Returning to the meta-analysis by Steblay et al. [4], it was found that the show-up procedure had a similar proportion of correct identifications in target-present conditions (47\%) compared to the lineup procedure (45\%). Yet, what is important to note is that the choosing rate was much lower for the show-up procedure (46\%) than the lineup procedure (71\%) for target present conditions. In other words, whereas nearly all of the show-up identifications were correct, many of the lineup identifications were incorrect, even when the target was present. For target absent conditions, a higher percentage (85\%) of witnesses rejected (i.e., said the perpetrator was not 
there) when they were presented with a show-up compared to a lineup (57\%). However, all witnesses who mistakenly identified someone from a show-up (15\%) made a mistaken identification whereas not all witnesses who mistakenly identified someone from a lineup made a false identification of an innocent suspect. So although $43 \%$ of the witnesses who were presented with a target absent lineup made a selection, only $16 \%$ of them actually identified the suspect (and not a filler). Using this number instead, we can conclude that the false identification rate is approximately the same between the show-up and the lineup procedure. Yet, this high number for the lineup procedure suggests that the included studies probably did not have entirely unbiased lineups (i.e., lineups where all members of the lineup are at equal chance of being selected, given that the suspect is innocent). Had this been the case, the false choosing rate would simply have been divided by the number of lineup members, which was 6 in these studies. This yields a false identification rate of $43 \% / 6=7.17 \%$, which is substantially smaller than the $15 \%$ for the show-up procedure. Thus, Dysart and Lindsay [2] argues that show-ups are significantly more likely to yield to false identifications. However, of course, this assumes that the lineups are not biased.

\section{Live Show-Up}

A live show-up refers to a show-up that presents the witness with a live encounter of the suspect instead of a photograph. This procedure is also known as a street identification in the UK [12]. In England and Wales, the Police and Criminal Evidence Act [13] established that it is allowed to use a live show-up if the identity of the suspect is unknown. For instance, this can involve a victim being taken on a drive around the area to see if it is possible for the victim to identify the suspect in order to obtain evidence to justify an arrest. In the already mentioned meta-analysis by Steblay et al. [4], it was found that show-ups generated more correct rejections than lineups irrespective of whether the procedure was conducted live or by photographs. These results are limited by the fact that only two studies of the hypothesis were included in the meta-analysis. In a more recent study examining the usefulness of the live show-up procedure using several experiments, participants became witnesses to a staged event where a student approached an experimenter in a classroom and criticized the experimenter for accusing the person of plagiarism [12]. Participants were soon after presented with either a live show-up or a video lineup that did or did not include the intruder. Interestingly, the results from one of the studies showed that fewer participants correctly identified the target when presented with a live show-up (51\%) compared to a video lineup (72\%). No significant differences were found for the target absent condition. However, this finding was not replicated in an additional experiment in the same study, where the live show-up condition had the highest accuracy. One reason for this may have been that the intruder in the later experiment had a distinctive gait which potentially made him easier to recognize in a live show-up. In other words, live show-ups does not seem to contribute anything to correct identification accuracy (potentially the opposite) if the information provided by the live show-up does not provide enough distinctive information of the culprit. Yet, it could perhaps assist identification accuracy if the culprit has a distinctive feature that is easier to recognize from a live show-up than a video lineup or show-up (e.g., gait).

\section{Clothing Bias}

Clothing bias refers to the clothes that the suspect is wearing at the time of the show-up. This can be a reliable source of influence, especially if the suspect is wearing clothes that matches the description of the perpetrator's clothes made by the witness [2]. For example, one study presented participants (store employees) with a showup after having interacted with a person with either common (blue-gray shirt) clothing or uncommon (a Harley-Davidson T-shirt) clothing [14]. Results showed that there was no significant increase in correct selections when the target (i.e., the person seen before) was wearing the same or similar clothing as during the encoding event. However, when the target wore clothing that were considered to be uncommon, this had a significant effect on identification accuracy. More interestingly, when the witnesses were presented with a highly similar looking foil face with similar clothing to that worn by the target, there was a significant increase in false identifications. This suggests that clothing bias is potentially very powerful and that a person who resembles the offender and has similar clothing (and is close to the crime scene) may be at significant risk of being mistakenly identified as the perpetrator when police are using the show-up procedure. Supporting the danger of clothing bias, Yarmey, Yarmey, and Yarmey [15] did a similar study and found that when witnesses viewed a show-up, including a similar suspect in similar clothing as that worn by the target, they made significantly more false identi- 
fications compared to if the suspect was wearing dissimilar clothing. It is important to note that none of these studies did find that the clothing bias was apparent with suspects that were not similar in appearance to the target. This is reasonable, as it is likely that the difference between the suspect's and the target's face would tend to offset any effects of the similar clothing [2]. In other words, witnesses might be able to distinguish between two different dissimilar looking persons in similar clothing but have a harder time distinguishing between two different similar looking persons in similar clothing.

\section{Instruction Bias}

When a show-up is biased in its instructions, it leads the witness to think that a no choice response is discouraged and that the perpetrator is in the show-up and that the witness' job is to just "pick the guy out" [2]. A meta-analysis reviewing studies about lineups found that a significantly higher amount of choosing occurred for lineups that had biased instructions (i.e., instructions that did not state that the perpetrator may or may not be present in the lineup) compared to unbiased instructions [16]. Researchers have even found that lineups can also be biased after the witness has made an identification by increasing witnesses' confidence in that they have made a correct identification [17]. This can be done by confirming to the witness that he or she picked the right person from a lineup (e.g., "good, you identified the suspect"). Thus, it appears that the instructions given both before and after a potential identification can have a large impact on witnesses. In line with these findings, a recent study by Smith et al. [3] had witnesses attempt identifications from show-ups with either unbiased instructions (e.g., it is just as important to clear innocent suspects as to identify the guilty perpetrator. The police investigation will continue even if you do not make an identification) or no unbiased instructions. It was found that witnesses who were presented with the unbiased instructions were significantly more likely to reject innocent suspects compared to witnesses who did not receive these instructions. This suggests that the influence of biased instructions holds true, in addition to lineups, also for show-ups.

\section{Time Delay}

In psychology, when talking about memory, it is common to refer to the forgetting curve. This refers to the exponential decay of memory over time such that forgetting occurs at a very high rate close to the encoding of the information but slows down as time goes by [18]. Considering the long history of this concept, it is not surprising that most eyewitness experts in the field (83\%) indicated that they believed that this psychological phenomenon is reliable enough to present in court [10]. Based on the scientific literature, it seems relatively clear that time delay impacts face memory negatively. For example, one meta-analysis by Deffenbacher, Bornstein, McGorty, and Penrod [19] that investigated 53 facial memory studies, demonstrated that longer time delays were associated with higher forgetting of previously seen faces. In terms of the show-up procedure, the previously mentioned study by Yarmey, Yarmey, and Yarmey [15] also found that correct identifications from a target present show-up and false identifications from a target absent show-up were lower and higher respectively, after a longer time delay (i.e., two or 24 hours). However, caution is important when interpreting these results since the study did not specifically test the main effects of time delay on show-up accuracy. In contrast, a study by Dysart, Lindsay, and Dupuis [14] found no effects of time delay (ranging from 10 minutes to 4 hours after the event) on identification accuracy from show-ups. The finding of a non-significant effect of time delay from show-ups (i.e., immediately or 48 hours) was also replicated in a more recent study [20], suggesting that the show-up procedure may exhibit smaller detrimental effects of time delay than lineups. In other words, we have to be careful in over-generalizing the findings of reduced face memory more generally to also include show-ups and more research is clearly needed in this area.

\section{The Impact of Multiple Show-Ups}

If police are conducting a show-up shortly after a crime has been committed, they have likely invested little effort in investigating a single suspect. Perhaps because the suspect fit the description provided by the witness, he or she may be placed in a show-up in order for the police to see if the witness recognizes and identifies the person. However, if the witness rejects the show-up, it is not unlikely to assume that they will find another suspect that matches the description of the perpetrator and conduct a new show-up, this time with a new suspect. Indeed, the outcome of a police survey by Smith et al. [3] found that $46 \%$ of the surveyed Canadian police officers and 
44\% of American police officers answered that they sometimes had conducted more than one show-up with the same eyewitness during the last year. In order to examine the influence of multiple show-ups on eyewitness accuracy, Smith et al. [3] had witnesses view several show-ups before being presented with the target. In study 2, the targets (i.e., the perpetrators in a real crime investigation) were presented in the first, fourth, or seventh show-up respectively. Alarmingly, the results showed that the innocence risk (the probability that the suspect is innocent given identification) increased dramatically from the first to the fourth and seventh show-ups. In the first show-up, there was a 31\% chance that the suspect was innocent, given that he was identified. For the fourth show-up, however, that number increased to $83 \%$ ! This means that there was an $83 \%$ probability (when presented with four show-ups) that the suspect was innocent, given that he was identified. Study 3 used a similar design but improved the limitations of the second study by increasing the retention interval (from 20 - 210 seconds to 20 minutes) to better simulate the time delay in a real crime investigation. It also presented the target in the first, second, third, fourth, and fifth show-up instead of only in the first, fourth, and seventh show-up to look at more fine grained effects of multiple show-ups on accuracy. In line with the results from study 2 , it was demonstrated that innocence risk was significantly lower in the first show-up (0.40) compared to the first two show-ups combined (0.75). No significant increase in innocence risk were observed after the second show-up. Consequently, both of these studies showed that even the use of two show-ups with the same eyewitness led to strikingly high levels of innocence risk. Hence, if police use more than one show-up with the same eyewitness, it is likely that the innocence risk of the suspect is already too high to be acceptable (i.e., $>0.50$ ).

\section{Carryover Effects}

Carryover effects refer to the occurrence when participation in an initial identification task (e.g., a show-up) carries over and influences the accuracy of subsequent identification tests (e.g., a lineup). In a study that investigated the influence of carryover effects from show-ups to lineups, participants were presented with a series of faces in an encoding phase [21]. Later they were presented with a series of target-present and target-absent show-ups and told to indicate whether the show-up face had been seen in the encoding phase. Finally, they were presented with a series of target-present and target-absent lineups and told to only identify the faces from the encoding phase and to not identify faces that had only been seen in the show-up phase. The outcome demonstrated that participants showed significant carryover effects such that the highest accuracy was observed when the target had been presented in all three phases of the experiment. More worrying, many participants also falsely identified a target face in a lineup that had only been shown during the show-up phase and not the encoding phase, indicating that they were unable to differentiate between these two different encoding occasions. Another study by Valentine et al. [12] examined the influence of carryover effects using live show-ups (see above) and found a strong support for a commitment effect (meaning that the participants who made a choice from a show-up also tended to choose from a subsequent lineup). However, no support were found for a carryover effect which suggests that participants were able to distinguish the face seen in a show-up from the actual face and not confuse the source of the two when presented with a lineup. Thus, the results of these two studies are somewhat mixed and we should therefore be cautious in making over-generalizations of the carryover effects from show-ups to lineups.

\section{Age}

Generally in eyewitness research, children and the elderly are two different groups that have been shown to be especially prone to making false identifications of innocent suspects. For instance, a study by Searcy, Bartlett, and Memon [22] compared the false identification rates between young adults and old adults and found that the old adults had a significantly higher false alarm rate than the young adults. Similarly, Pozzulo and Lindsay [23] demonstrated that children ( 9 - 10 and 12 - 13 years) also were significantly more likely to falsely identify an innocent suspect compared to adult witnesses. Thus, the reliability of these witnesses may be weakened. Importantly, these studies used lineups and not show-ups for obtaining their identifications which limits the conclusions that can be drawn about the influence of age on identifications from show-ups. Looking specifically at young children and the show-up procedure, Dekle, Beal, Elliott, and Huneycutt [24] found that young children (5 - 6 years old) were actually more likely to identify the perpetrator when she was present in the show-up procedure than adults were. However, in line with the previously mentioned lineup studies, they did significantly worse when the perpetrator was not included in the show-up (i.e., they had a higher false identification rate) 
compared to the adult sample. A similar study with a slightly older sample ( $M=6.5$ years) also found that the show-up procedure increased the correct identifications in a perpetrator present show-up but put innocent suspects of increased risk of being mistakenly identified when the show-up did not contain the perpetrator [25]. Thus, these studies imply that child witnesses may be at a higher risk of identifying innocent suspects from show-ups in comparison to adults but more research clearly needs to be done.

\section{Cross-Race Effect}

The cross-race effect in eyewitness research is a stable finding that people of a certain race have a harder time recognizing and identifying someone from another race. For example, a meta-analysis by Meissner and Bringham [26] compared 39 studies with nearly 5000 research participants to look for the impact of race on identification accuracy from lineups. Not surprisingly, they found that own race faces (often White faces) produced a higher proportion of correct identifications and a lower proportion of false identifications of innocent suspects than other race faces (often African American faces) ${ }^{2}$. In a more recent study, looking at Caucasians and First Nation participants, Jackiw, Arbuthnott, Pfeifer, Marcon, and Meissner [27] found that the general decrease in identification accuracy observed between Caucasian and African American faces also generalized to Caucasian and First Nation participants. In other words, the cross-race effect seem to be generalizable to other races rather than just the most commonly researched, namely Caucasian and African American faces. One recent study by Lawson and Dysart [28] investigated the cross-race effect, together with time delay and clothing bias, in showups by showing witnesses a short video of an own-race or another-race perpetrator and later had them attempt to identify the person from a show-up. Contrary to the cross-race effect, race did not significantly affect show-up choosing or accuracy. However, there was an interaction effect between race, clothing, and response time such that participants spent more time making a decision for other-race faces when the suspect's clothing was the same between the video and the show-up compared to when it was different. In contrast, participants spent more time making their decision for own-race faces when the suspect's clothing was different compared to when it was the same. Thus, this study only presents very limited support for the cross-race effect in show-ups. Yet, more research needs to be done in this area before definitive conclusions can be drawn about the cross-race effect in show-ups.

\section{Weapon Focus}

The influence of weapons on the memory of a criminal has been referred to as the weapon focus effect. More specifically, this effect occurs when an object draws attention away from the target, leading to a decrease in identification accuracy [2] [29]. A recent meta-analysis, investigating 28 different studies that looked at the weapon focus effect found that identification accuracy from lineups was lower when participants had been exposed to a weapon compared to when no weapon was shown [30]. Although the weapon focus effect has mostly been studied with weapons, other studies have found that it may not be the weapon per se that is driving the weapon focus effect but rather the unusualness of the object. For example, Pickel [31] did a study where a gun was carried by either a police officer (the usual condition) or a priest (the unusual condition). The results showed that the weapon only negatively influenced the witness's description accuracy of the priest and not the police officer. Accordingly, it could be argued that the object (a gun) is considered to be a common object among police officers but not among priests. While the research about the weapon focus is large when it comes to lineups, studies using show-ups is greatly missing from the literature. Consequently, more research on the weapon focus effect in show-ups would be clearly informative.

\section{Alcohol}

In the USA, $24.2 \%(1,175,275)$ of all crimes of violence and $30 \%(1,456,953)$ of all crimes of sexual assault and rape are believed to be committed by an offender under the influence of alcohol. This amounts up to a staggering number of over 2.6 million crimes that are committed under the influence of alcohol ever year [32]. Although the witnesses to these crimes are not always under the influence of alcohol, it is not unlikely that at least some of these witnesses may be under the influence of alcohol [2]. For example, a survey of law enforcement

\footnotetext{
${ }^{2}$ This reflects the fact that a lot of the research in this area has been done in North America with Caucasian students (See the meta-analysis by Meissner \& Bringham [26]).
} 
officers showed that it was not uncommon for them to deal with intoxicated witnesses and suspects at different times in the investigative process, such as at the crime scene or during an interview [33]. Thus, it is indeed important to establish the influence of alcohol on identification accuracy from show-ups and lineups. The detrimental effects of alcohol on eyewitness identifications are generally based on the theory of alcohol myopia [34]. This theory states that alcohol intoxication restricts the range of cues that can be perceived in a situation such that only the most prominent features will be attended to. It also emphasizes that people under the influence of alcohol have a harder time extracting meaning from the information that they do receive. It is therefore logical to assume that alcohol will have severe effects on the memory and identification accuracy of eyewitnesses. One study that specifically looked at alcohol intoxication and the show-up procedure found that witnesses who had higher levels of alcohol in their blood at the time of the identification (and presumably the event) did not differ in their proportions of correct identifications compared to those with lower levels of alcohol, when shown a target present show-up [35]. However, for witnesses who were shown a target absent show-up, false identifications increased as the blood alcohol levels went up. This suggests that intoxicated witnesses may be at risk of identifying an innocent suspect if the police conducts a show-up without the actual perpetrator. Interestingly, a study described by Dysart and Lindsay [2] demonstrated that witnesses under the influence of alcohol who were given cautious instructions (e.g., the perpetrator may not be in the show-up) were actually more influenced by the cautious instructions than were sober witnesses. These witnesses also showed the best accuracy (97\%) of all groups when shown a target absent show-up after having been given the cautious instructions. In other words, witnesses under the influence of alcohol may be more likely to identify an innocent suspect in a target absent show-up compared to sober witnesses, but they also may be more likely to change their behavior and be more cautious when given the right instructions.

\section{Conclusion}

As it is mentioned in the beginning of this literature review, the research about the show-up procedure is not nearly as substantial as the research about lineups. This obviously limits the certainty of our conclusions. However, the factors that have been demonstrated to influence identification accuracy from lineups are also likely to affect show-ups. As have been seen, the studies that have looked at the show-up procedure have shown that this procedure is highly prone to lead to innocent suspects being falsely identified [3] [4]. More specifically, the study by Smith et al. [3] found that the innocence risk was over 50\% (indicating that a suspect was more likely to be innocent than guilty) after the presentation of a second show-up. This may be enough for some people to recommend the elimination of this procedure completely. Yet, despite the apparent suggestiveness of the showup procedure, it is not desirable to exclude this procedure from the criminal justice system completely since it has many potential positive characteristics (e.g., to quickly identify the perpetrator and exclude an innocent suspect). Therefore, more research about this procedure is highly needed. For example, research is almost completely missing in terms of the cross-race effect (one published study) and the weapon focuses effect on show-ups. Dysart and Lindsay [2] similarly stated that more research needed to be done. Especially since this literature review has established that the show-up procedure is being used today by police officers in both USA and Canada and that it is likely that the police will continue to use these identification procedures no matter whether they are adequately researched or not.

\section{Acknowledgements}

The author would like to thank Professor Roderick Lindsay for all his help and support in writing this paper and for all our inspiring and interesting discussions. A special thank you is also directed to the anonymous reviewers who gave suggestions and comments which significantly increased the quality of this article.

\section{References}

[1] Wells, G.L. (1978) Applied Eyewitness-Testimony Research: System Variables and Estimator Variables. Journal of Personality and Social Psychology, 36, 1546-1557. http://dx.doi.org/10.1037/0022-3514.36.12.1546

[2] Dysart, J.E. and Lindsay, R.C.L. (2007a) Show-Up Identifications: Suggestive Technique or Reliable Method? In: Lindsay, R.C.L., Ross, D.F., Read, J.D. and Toglia, M.P., Eds., The Handbook of Eyewitness Psychology, Volume 2: Memory for People. Lawrence Erlbaum Associates, Mahwah, 137-153.

[3] Smith, A.M., Bertrand, M., Lindsay, R.C.L., Kalmet, N., Grossman, D. and Provenzano, D. (2014) The Impact of Mul- 
tiple Show-Ups on Eyewitness Decision-Making and Innocence Risk. Journal of Experimental Psychology: Applied, 20, 247-259. http://dx.doi.org/10.1037/xap0000018

[4] Steblay, N., Dysart, J.E., Fulero, S. and Lindsay, R.C.L. (2003) Eyewitness Accuracy Rates in Police Showup and Lineup Presentations: A Meta-Analytic Comparison. Law and Human Behavior, 27, 523-540. http://dx.doi.org/10.1023/A:1025438223608

[5] Steblay, N.K., Dysart, J.E. and Wells, G.L. (2011) Seventy-Two Tests of the Sequential Lineup Superiority Effect: A Meta-Analysis and Policy Discussion. Psychology, Public Policy, and Law, 17, 99-139. http://dx.doi.org/10.1037/a0021650

[6] Wells, G.L. (1984) The Psychology of Lineup Identifications. Journal of Applied Social Psychology, 14, 89-103. http://dx.doi.org/10.1111/j.1559-1816.1984.tb02223.x

[7] Agricola, B.H. (2009) The Psychology of Pretrial Identification Procedures: The Showup Is Showing out and Undermining the Criminal Justice System. Law and Psychology Review, 33, 125-137.

[8] Wells, G.L., Small, M., Penrod, S., Malpass, R.S., Fulero, S.M. and Brimacombe, C.A.E. (1998) Eyewitness Identification Procedures: Recommendations for Lineups and Photospreads. Law and Human Behavior, 22, 603-647. http://dx.doi.org/10.1023/A:1025750605807

[9] Lindsay, R.C. and Wells, G.L. (1985) Improving Eyewitness Identifications from Lineups: Simultaneous versus Sequential Lineup Presentation. Journal of Applied Psychology, 70, 556-564. http://dx.doi.org/10.1037/0021-9010.70.3.556

[10] Kassin, S.M., Tubb, V.A., Hosch, H.M. and Memon, A. (2001) On the “General Acceptance” of Eyewitness Testimony Research: A New Survey of the Experts. American Psychologist, 56, 405-416. http://dx.doi.org/10.1037/0003-066X.56.5.405

[11] Malpass, R.S., Tredoux, C.G. and McQuiston-Surrett, D. (2007b) Lineup Construction and Lineup Fairness. In: Lindsay, R.C.L., Ross, D.F., Read, J.D. and Toglia, M.P., Eds., The Handbook of Eyewitness Psychology, Volume 2: Memory for People, Lawrence Erlbaum Associates, Mahwah, 137-153.

[12] Valentine, T., Davis, J.P., Memon, A. and Roberts, A. (2012) Live Showups and Their Influence on a Subsequent Line-Up. Applied Cognitive Psychology, 26, 1-23. http://dx.doi.org/10.1002/acp.1796

[13] Police and Evidence Criminal Act 1984 — Code of Practice, Code D (2008) Code of Practice for the Identification of Persons by Police Officers. https://www.gov.uk/government/uploads/system/uploads/attachment_data/file/117599//pace-code-d.pdf

[14] Dysart, J.E., Lindsay, R.C.L. and Dupuis, P.R. (2006) Show-Ups: The Critical Issue of Clothing Bias. Applied Cognitive Psychology, 20, 1009-1023. http://dx.doi.org/10.1002/acp.1241

[15] Yarmey, A.D., Yarmey, M.J. and Yarmey, A.L. (1996) Accuracy of Eyewitness Identifications in Showups and Lineups. Law and Human Behavior, 20, 459-477. http://dx.doi.org/10.1007/BF01498981

[16] Steblay, N.M. (1997) Social Influence in Eyewitness Recall: A Meta-Analytic Review of Lineup Instruction Effects. Law and Human Behavior, 21, 283-297. http://dx.doi.org/10.1023/A:1024890732059

[17] Wells, G.L. and Bradfield, A.L. (1998) “Good, You Identified the Suspect”: Feedback to Eyewitnesses Distorts Their Reports of the Witnessing Experience. Journal of Applied Psychology, 83, 360-376. http://dx.doi.org/10.1037/0021-9010.83.3.360

[18] Loftus, G.R. (1985) Observations: Evaluating Forgetting Curves. Journal of Experimental Psychology: Learning, Memory, and Cognition, 11, 397-406. http://dx.doi.org/10.1037/0278-7393.11.2.397

[19] Deffenbacher, K.A., Bornstein, B.H., McGorty, E.K. and Penrod, S.D. (2008) Forgetting the Once-Seen Face: Estimating the Strength of an Eyewitness’s Memory Representation. Journal of Experimental Psychology: Applied, 14, 139-150. http://dx.doi.org/10.1037/1076-898X.14.2.139

[20] Wetmore, S.A., Neuschatz, J.S., Gronlund, S.D., Wooten, A., Goodsell, C.A. and Carlson, C.A. (2015) Effect of Retention Interval on Showup and Lineup Performance. Journal of Applied Research in Memory and Cognition, 4, 8-14. http://dx.doi.org/10.1016/j.jarmac.2014.07.003

[21] Haw, R.M., Dickinson, J.J. and Meissner, C.A. (2007) The Phenomenology of Carryover Effects between Show-Up and Line-Up Identification. Memory, 15, 117-127. http://dx.doi.org/10.1080/09658210601171672

[22] Searcy, J.H., Bartlett, J.C. and Memon, A. (1999) Age Differences in Accuracy and Choosing in Eyewitness Identification and Face Recognition. Memory \& Cognition, 27, 538-552. http://dx.doi.org/10.3758/BF03211547

[23] Pozzulo, J.D. and Lindsay, R.C.L. (1998) Identification Accuracy of Children versus Adults: A Meta-Analysis. Law and Human Behavior, 22, 549-570. http://dx.doi.org/10.1023/A:1025739514042

[24] Dekle, D.J., Beal, C.R., Elliott, R. and Honeycutt, D. (1996) Children as Witnesses: A Comparison of Lineup versus Showup Identification Methods. Applied Cognitive Psychology, 10, 1-12. 
http://dx.doi.org/10.1002/(SICI)1099-0720(199602)10:1<1::AID-ACP354>3.0.CO;2-Y

[25] Beal, C.R., Schmitt, K.L. and Dekle, D.J. (1995) Eyewitness Identification of Children: Effects of Absolute Judgements, Nonverbal Response Options, and Event Coding. Law and Human Behavior, 19, 197-216. http://dx.doi.org/10.1007/BF01499325

[26] Meissner, C.A. and Bringham, J.C. (2001) Thirty Years of Investigating the Own-Race Bias in Memory for Faces: A Meta-Analytic Review. Psychology, Public Policy, and Law, 7, 3-35. http://dx.doi.org/10.1037/1076-8971.7.1.3

[27] Jackiw, L.B., Arbuthnott, K.D., Pfeifer, J.E., Marcon, J.L. and Meissner, C.A. (2008) Examining the Cross-Race Effect in Lineup Identification Using Caucasian and First Nation Sample. Canadian Journal of Behavioral Science, 40, 52-57. http://dx.doi.org/10.1037/0008-400x.40.1.52

[28] Lawson, V.Z. and Dysart, J.E. (2014) The Showup Identification Procedure: An Exploration of Systematic Biases. Legal and Criminological Psychology, 19, 54-68. http://dx.doi.org/10.1111/j.2044-8333.2012.02057.x

[29] Steblay, N.M. (1992) A Meta-Analytic Review of the Weapon Focus Effect. Law and Human Behavior, 16, $413-424$. http://dx.doi.org/10.1007/BF02352267

[30] Fawcett, J.M., Russell, E.J., Peace, K.A. and Christie, J. (2013) Of Guns and Gees: A Meta-Analytic Review of the “Weapon Focus” Literature. Psychology, Crime, \& Law, 19, 35-66. http://dx.doi.org/10.1080/1068316X.2011.599325

[31] Pickel, K.L. (1999) The Influence of Context on the "Weapon Focus” Effect. Law and Human Behavior, 23, $299-311$. http://dx.doi.org/10.1023/A:1022356431375

[32] US Department of Justice (2008) Criminal Victimization in the United States, 2008 Statistical Tables. NCJ Publication No. 227669. US Department of Justice, Washington DC.

[33] Evans, J.R., Compo, N.S. and Russano, M.B. (2009) Intoxicated Witnesses and Suspects: Procedures and Prevalence According to Law Enforcement. Psychology, Public Policy, and Law, 15, 194-221. http://dx.doi.org/10.1037/a0016837

[34] Steele, C.M. and Josephs, R.A. (1990) Alcohol Myopia: Its Prized and Dangerous Effects. American Psychologist, 45, 921-933. http://dx.doi.org/10.1037/0003-066X.45.8.921

[35] Dysart, J.E., Lindsay, R.C.L., MacDonald, T.K. and Wicke, C. (2002) The Intoxicated Witness: Effects of Alcohol on Identification Accuracy from Show-Ups. Journal of Applied Psychology, 87, 170-175. http://dx.doi.org/10.1037/0021-9010.87.1.170 